\title{
Toxicological risks of water and human health, contribution to the biological treatments in the dam of Ain Zada
}

\section{Type of article: Conference abstract}

\author{
Bariza Gourari ${ }^{1}$, Djamel Anteur ${ }^{2}$
}

1. Department of Biology, Faculty of Science, the University of El Bez, Setif, Algeria

2. Université Moulay Tahar, Faculté des Sciences, Département de Biologie, Algeria

barizabio12@gmail.com

\begin{abstract}
Background: Freshwater fish play a role in detoxification of certain germs and pathogens of bacteria. Variation of the content of pathogenic bacteria are, mainly, total coliform, fecal coliform, and fecal streptococci in the study sites of the sampling period. The objective of this study is inventoried purifying species of dam of Ain Zada.
\end{abstract}

Methods: The isolation of fecal coliform (CF) and total coliform (CT) was conducted by incorporation in agar of the five shot test $(0,4 \mathrm{~mL} ; 1 \mathrm{~mL}$ et $3 \times 2 \mathrm{~mL})$. The culture medium is the selective agar Mac Conkey (HIMEDIA, M083) coliforms. The enumeration of the colonies is done after 24 of incubation at $37^{\circ} \mathrm{C}$ for total coliforms and $44^{\circ} \mathrm{C}$ for fecal coliforms. The isolation of fecal streptococci (SF) is made by the same method but on the culture medium incubated at $37^{\circ} \mathrm{C}$ for 48 hours. Counting of colonies is done on mailboxes where 100 to 300 colonies are developed. The average of colonies counted is then determined. The boxes do not contain at least 100 colonies, all of the colonies on all boxes are counted, taking into account the total volume inoculated in water. In the second part, there is an inventory of purifying fish at the Ain Zada dam level.

Results: The result indicate that all the fish that play a role in the treatment of dam of Ain Zada (Bordj Bou Arreridj) who use these germs and bacteria as a food source. We registered the presence of a single family, with five (05) genera divided into seven (07) species, including the majority of alien species are Cyprinid fish: Sander lucioperca L., Ctenopharyngodon idella, Clarias gariepinus, Cyprinus carpio, Hypophthalmichthys molitrix and Hypophtalmichthys nobilis.

Conclusion: The Bousselam and Ouricia valleys feature heavily poor microbiological quality; exploitation of these waters could constitute a health hazard on dam Ain Zada. According to this study, the fish play a role of biological control.

Keywords: Fish, dam Ain Zada, detoxification 


\section{Declaration of conflicts}

This article was selected from the International Conference of Health Sciences and Medical Technologies 2016 ICHSMT'16 abstracts book.

\section{Authors' biography}

No Biography

\section{References}

No references 